\title{
Associations of mindfulness with adolescent outcomes and sexuality
}

Chelom E. Leavitt

Brigham Young University - Provo

David B. Allsop

Brigham Young University - Provo

Dean M. Busby

Brigham Young University - Provo, dean_busby@byu.edu

Shayla M. Driggs

Brigham Young University - Provo

Heather M. Johnson

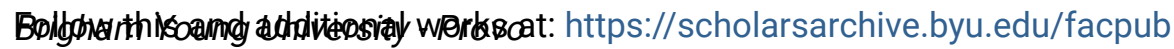

Part of the Other Social and Behavioral Sciences Commons

See next page for additional authors

Original Publication Citation

Leavitt, C. E., Allsop, D. B., Busby, D. M, Driggs, S. M. Johnson, H. M., \& Saxey, M. T. (2020).

Associations of mindfulness with adolescent outcomes and sexuality. Journal of Adolescence,

8, 73-86.

\section{BYU ScholarsArchive Citation}

Leavitt, Chelom E.; Allsop, David B.; Busby, Dean M.; Driggs, Shayla M.; Johnson, Heather M.; and Saxey, Matthew T., "Associations of mindfulness with adolescent outcomes and sexuality" (2020). Faculty Publications. 4645.

https://scholarsarchive.byu.edu/facpub/4645

This Peer-Reviewed Article is brought to you for free and open access by BYU ScholarsArchive. It has been accepted for inclusion in Faculty Publications by an authorized administrator of BYU ScholarsArchive. For more information, please contact ellen_amatangelo@byu.edu. 
Authors

Chelom E. Leavitt, David B. Allsop, Dean M. Busby, Shayla M. Driggs, Heather M. Johnson, and Matthew T. Saxey 


\title{
Associations of mindfulness with adolescent outcomes and sexuality
}

\author{
Chelom E. Leavitt*, David B. Allsop, Dean M. Busby, Shayla M. Driggs, \\ Heather M. Johnson, Matthew T. Saxey
}

The School of Family Life, Brigham Young University, USA

\section{A R T I C L E I N F O}

\section{Keywords:}

Adolescent sexuality

Mindfulness

Sexual mindfulness

Adolescent disclosure

Adolescent body-esteem

\begin{abstract}
A B S T R A C T
Introduction: Using an online survey, we evaluated how adolescent trait and state mindfulness was associated with positive adolescent outcomes in non-sexually active and sexually active adolescents. Additionally, we evaluated a newly developed measure, the Sexual Mindfulness Measure (SMM), with adolescents.

Methods: We asked 2000 U.S. adolescents (half boys/girls; 1/3 low, medium, and high incomes) aged 13-18 (one group 13-15, another 16-18) about trait mindfulness, sexual state mindfulness, and adolescent outcomes. Using Confirmatory Factor Analysis and structured equation modeling, we evaluated the reliability and validity of the SMM and its associations with adolescent outcomes.

Results: Using a trait mindfulness measure, we found that mindful adolescents with no sexual experience, showed positive associations with self-efficacy, body-esteem, and disclosure with both fathers and mothers. Evaluating adolescents who were sexually active, we confirmed that the SMM had a two-factor structure and demonstrated acceptable reliability for both male and female adolescents. We found that the SMM was associated with positive sexual attitudes, body image, self-efficacy, and disclosure to parents above and beyond trait mindfulness.

Conclusions: Trait mindfulness was associated with positive self-assessments and parental disclosure. The SMM provided an important assessment of how sexually active adolescents' ability to remain aware and non-judgmental during sexual experiences may be positively associated with outcomes such as sexual consent, positive body image, self-efficacy, disclosure to parents, and negatively associated with sexual shame and sexual anxiety above and beyond trait mindfulness.
\end{abstract}

\section{Introduction}

Mindfulness in everyday activities and during sexual experiences has shown a number of positive associations with adult individual, relational, and sexual outcomes (Newcombe \& Weaver, 2016; Pepping, Cronin, Lyons, \& Caldwell, 2018). Research on the benefits of trait mindfulness for adolescents is needed, but is sparse (Bluth and Blanton, 2014; Tan, 2016). During adolescence when youth are developing attitudes and behavior patterns, verbal skills and cognitive processes (Kar, Choudhury, \& Singh, 2015) a mindful approach may be particularly meaningful. Greater trait mindfulness may help adolescents navigate the difficult path around issues such as how they feel about their body, their ability to execute their own ideas, their confidence in their own worth, their own

\footnotetext{
${ }^{*}$ Corresponding author. Brigham Young University, 2054 JFSB Provo, Utah, 84604, USA.

E-mail address: Chelom_leavitt@byu.edu (C.E. Leavitt).
} 
sexuality and, when sexually-active, the need to gain permission to express their sexuality with another. In an environment of pressure to have sex that may include lack of sexual consent (Hawkes et al., 2019), adolescents may benefit from the skills of trait mindfulness and possibly sexual mindfulness, which encourages a more deliberate thought process and intentionality in behavior. To examine the state of mindfulness within a sexual context, a reliable sexual mindfulness measure within an adolescent sample is required.

Adult trait mindfulness measures that examine the ability to remain aware and non-judgmental of present experiences have been used or modified to examine the trait mindfulness levels in adolescents (Brown, West, Loverich, \& Biegel, 2011; Greco, Baer, \& Smith, 2011). Trait mindfulness may be seen as a trait characteristic, an inherent disposition to be mindful. State mindfulness examines the level of mindfulness during a particular interaction in daily life (Brown \& Ryan, 2003). In adult romantic relationships, both trait and state mindfulness are linked with satisfaction in relational and sexual experiences (Barnes et al., 2007; Leavitt, Lefkowitz, \& Waterman, 2019). Sexual mindfulness is a type of state mindfulness. Examining mindfulness during a sexual experience provides a measure of the individual's ability to remain mindful during particular situations, including the potentially high arousal/anxiety context of sex. The Sexual Mindfulness Measure (SMM) has been validated in an adult sample (Leavitt, Lefkowitz et al., 2019), but not with an adolescent sample. Examining the level of mindfulness during sexual experiences may provide insight into the process of adolescent sexual decisions. More mindful adolescents may be able to slow the process of sexual arousal, thought processes, and decisions to be more purposeful and intentional, which may result in less regret and more satisfaction with sexual decisions. Consequently, we expect to find that adolescents who report more trait mindfulness and sexual mindfulness (state) will also report more positive outcomes such as self-esteem, body-esteem, self-efficacy, and parental disclosure and if sexually active, more positive sexual attitudes. We use previous findings from adult samples to guide the present research.

\subsection{Adolescents and trait mindfulness}

Adolescent trait and state mindfulness may be particularly important to understand as adolescence is a challenging developmental stage. Adolescents are highly self-critical and may feel alone or disconnected (Jacobs, Lanza, Osgood, Eccles, \& Wigfield, 2002, https://link.springer.com/article/10.1007/s10826-013-9830-2). The small amount of research on adolescent trait mindfulness indicates its influence on lower negative and higher positive affect (Broderick and Metz, 2009, https://link.springer.com/article/10. 1007/s10826-013-9830-2; Schonert-Reichl \& Lawlor, 2010, https://link.springer.com/article/10.1007/s10826-013-9830-2), less stress (Biegel et al., 2009, https://link.springer.com/article/10.1007/s10826-013-9830-2), improved emotional well-being (Bluth and Blanton, 2014), and increased psychological well-being (Huppert and Johnson, 2010, https://link.springer.com/article/10. 1007/s10826-013-9830-2). Additionally, a mindfulness practice has a protective factor against burn out in young athletes (Gustafsson, Skoog, Davis, Kenttä, \& Haberl, 2015; Zhang, Si, Chung, \& Gucciardi, 2016). These initial studies of dispositional mindfulness or mindfulness training are promising as they indicate that although measures need to be developmentally sensitive to the emotional and cognitive ability of adolescents, mindfulness can be measured and used to understand adolescent outcomes.

\subsection{Adolescents and sexual mindfulness}

While a majority of adolescents engage in sexual activity by their late teens (Halpern, Waller, Spriggs, \& Hallfors, 2006), a significant percentage of teens do not and some who are sexually active do so because they felt pressure or coercion to do so (Hawks et al., 2019). Helping adolescents to gain a positive attitude toward their sexual development, whether they are sexually active or not, preventing health risks associated with risky sexual behaviors (Halpern et al., 2006; Haydon, Herring, \& Halpern, 2012), and helping them to make more intentional decisions has been a research focus in recent decades. In adult samples, examining mindfulness within a sexual experience (state mindfulness) has shown predictive ability above trait mindfulness for associations with self-esteem, relational, and sexual satisfaction (Leavitt, Lefkowitz et al., 2019). Being mindful during a sexual experience may be more difficult than being mindful in other day to day experiences. Even individuals who are mindful in other daily activities (such as while walking or in everyday conversations) may find it difficult to remain mindful during sexual experiences. Sex may present additional obstacles/ rewards such as heightened sexual arousal and pleasure, sexual anxiety, sexual goals, or self-criticism (McCabe et al., 2010). These obstacles/rewards may make intentional decision-making more challenging, particularly for adolescents. Consequently, trait mindfulness may be helpful but may not generalize to achieving mindfulness during sexual experiences. Just like adults, adolescents may be prone to engaging in sexual experiences due to sexual role expectations (Goldsmith, Dunkley, Dang, \& Gorzalka, 2017), pressure, or without slowing down their thought process, being aware of their moment-to-moment arousal, or remaining nonjudgmental in the evaluations of the experience (Lazaridou \& Kalogianni, 2013; Leavitt, Lefkowitz et al., 2019). Research explained that the still developing adolescent brain may be vulnerable to impulsive, unreasoned decisions (Whelan et al., 2012). However, other research indicated mindfulness skills are linked to an ability to refrain from maladaptive impulsivity (Peters, Erisman, Upton, Baer, \& Roemer, 2011). As adolescents develop their sexuality (whether sexually active or not) they are also developing their identity. Research has indicated that more mindful young adults present themselves more authentically in social media settings and report higher self-esteem (Yang, Holden, \& Carter, 2017). Identity development requires time for adolescents to reflect on their self-presentation, interactions with others (https://www.sciencedirect.com/science/article/pii/S019339731730045X Harter, 2012), which mindfulness skills may encourage. Consequently, understanding the level of sexual mindfulness may provide researchers, therapists, and counselors an important perspective on how to encourage adolescents to gain a positive sexual attitude, a positive evaluation of their developing body, feelings of self-efficacy, the use of intentional sexual decisions, and the ability to disclose information about sexual experiences to their parents. 
The Sexual Mindfulness Measure has been validated in an adult sample (Leavitt, Lefkowitz et al., 2019) and used in a number of studies examining sexual outcomes (Busby, Leonhardt, Leavitt, \& Hanna-Walker, 2020; Leavitt, Leonhardt, \& Busby, 2019; Leavitt, Lefkowitz, Akyil, \& Serduk, 2020). No gender differences were noted in the SMM's reliability for adults. Being more aware and less judgmental during sex appears to be useful for both women and men and we expect that the SMM will work similarly for adolescent boys and girls.

\subsection{Positive adolescent outcomes}

A number of variables have been associated with positive adolescent outcomes that help smooth some of the bumps of this developmental stage. For example, nurturing feelings of empathy, compassion toward oneself and others (Barker, 2017), encouraging self-efficacy (e.g., Fallah, 2017), and body-esteem (Voelker, Petrie, Huang, \& Chandran, 2019), may provide a healthy platform for this stage of development. These outcomes may be more attainable for adolescents who can slow their thought process and refrain from impulsive judgments or behavior, a common risk factor for adolescents (Whelan et al., 2012). Additionally, for adolescents who are sexually active, avoiding attitudes of shame or anxiety may play an important role in their healthy development. We examine a few of these variables.

Self-esteem. Trait mindfulness has shown positive associations with psychological health of adults and adolescents, particularly with self-esteem (Tan \& Martin, 2016). A systematic review of mindfulness and self-esteem showed trait mindfulness was positively associated with young adult and adult self-esteem and self-esteem increased during mindfulness interventions (Randal, Pratt, \& Bucci, 2015). Although no research has examined the association of sexual mindfulness and adolescent self-esteem, research with an adult sample showed a positive association (Leavitt et al., 2020).

Body-esteem. The current literature has not yet considered the effects trait mindfulness may have on body-esteem for the adolescent population. However, we draw on literature from young adults attending university to evaluate the possible associations between adolescent mindfulness and body-esteem. Although these studies have shown a general positive relationship between trait mindfulness and body satisfaction some factors of trait mindfulness did not necessarily encourage greater body-esteem in college age samples (Dekeyser, Raes, Leijssen, Laysen, \& Dewulf, 2008; bib_Voelker_et_al_2019Voelker et al., 2019). Among adults, trait mindfulness has proven to decrease the drive for muscularity in men, decrease body comparison in women, and increase body image generally (Dijkstra \& Barelds, 2011; Lavender, Gratz, \& Anderson, 2012).

Self-efficacy. A few studies addressed mindfulness and self-efficacy among university students. For example, trait mindfulness has been positively associated with academic self-efficacy after a perceived failure, and with greater coping self-efficacy (Fallah, 2017; Hanley, Palejwala, Hanley, Canto, \& Garland, 2015; Wei, Tsai, Lannin, Du, \& Tucker, 2015). Other scholars found that selfefficacy significantly mediated the relationship between mindfulness and a third variable such as non-suicidal self-injury, foreign language anxiety, and emotional exhaustion (Charoensukmongkol \& Suthatorn, 2018; Fallah, 2017; Heath, Joly, \& Carsley, 2016). Furthermore, trait mindfulness and self-efficacy together can predict a third variable, such as psychological well-being and resilience (Keye \& Pidgeon, 2013; Klainin-Yobas et al., 2016).

Disclosure to parents. Preliminary research on parent-child communication and mindfulness has been focused on mindful parenting. Mindful parenting was positively associated with adolescents' disclosure to mothers and lower mother-adolescent conflict intensity (Kil, 2018). Three factors may explain why mindful parenting improves parent-child communication (Lippold, Duncan, Coatsworth, Nix, \& Greenberg, 2015). Mindful parenting and parent-child communication was mediated by the negative parental reactions to disclosure, adolescent feelings of parental over-control, and the affective quality of the parent-adolescent relationship (Lippold et al., 2015). However, no research, to our knowledge, has examined whether mindful adolescents are more likely to disclose to parents.

Sexual attitudes. Sexual shame has shown a negative association with trait mindfulness for sexual minority adolescents in therapy (Tan \& Yarhouse, 2010) and adult men with hypersexual or compulsive sexual disorders (Brem, Shorey, Anderson, \& Stuart, 2017; Reid, Temko, Moghaddam, \& Fong, 2014). Mindfulness practice has also been mentioned as a tool to alleviate sex-related shame and negative thoughts about sex in adult women (Morton \& Gorzalka, 2013; Woo, Brotto, \& Gorzalka, 2011). No research has examined how sexual mindfulness may be negatively associated with sexual shame.

The association of sexual consent and trait or state mindfulness has not been examined, yet is salient in today's environment. Mindfulness research consistently emphasizes the ethical treatment of oneself and others (Barker, 2017). Mindfulness encourages loving-kindness, empathy, and compassion, particularly in a sexual setting (Barker, 2017) and thereby may be positively associated with attitudes of consent in an adolescent sample.

Sexual esteem. or the confidence or efficacy an individual feels in experiencing sexual pleasure and satisfaction (Tan \& Yarhouse, 2010), is linked to a host of positive sexual outcomes (McCabe \& Taleporos, 2003). Sexual esteem is lowered when individuals feel unable to express their sexual desire due to physical limitations (McCabe \& Taleporos, 2003) or other emotional limitations. There is no research linking sexual esteem and mindfulness. However, because mindfulness encourages a process of awareness and nonjudgment, it is likely that the two variables will be positively associated.

Research has also shown that mindfulness may reduce sexual anxiety among a broad population (Dunkley, Goldsmith, \& Gorzalka, 2015; Kimmes, Mallory, Cameron, \& Köse, 2015). Anxiety is a common factor in sexual dysfunction (Kimmes, Mallory, Cameron, \& Köse, 2015). Adults who learned and practiced mindfulness techniques reported reduced pain disorders, sexual dysfunction, and sexual insecurities (Dunkley et al., 2015; Kimmes et al., 2015). 


\subsection{The current study}

In this study we attempt to explore the relationship of trait mindfulness with both sexually active and inactive youth and with those who are sexually active we explore how well a measure of sexual mindfulness functions and may be associated with important outcomes such as consent and self-esteem. Mindfulness may play a particularly salient role during adolescent sexual development, whether or not adolescents are engaging in any sexual behaviors. Adolescence is a time of rapid change and exploration and adolescents' brains are not yet fully developed which is linked with an increased tendency for impulsive and risky behavior (Whelan et al., 2012). However, sexual feelings, physical changes, and relationships are new and as adolescents try to navigate the feelings, physical changes, and relational aspects of their sexuality, trait mindfulness and sexual mindfulness may allow adolescents added time to process these feelings and changes.

Specifically, we hypothesize:

1. With non-sexually active adolescents, trait mindfulness will be positively associated with sexual consent beliefs, body-image, selfefficacy, and disclosure to parents.

Additionally, with sexually active adolescents, we examine the use of the Sexual Mindfulness Measure (SMM; Leavitt, Lefkowitz et al., 2019). We examine the reliability and validity of the SMM. Specifically, we predict the following four hypotheses:

2. Construct validity: The SMM would maintain a two-factor structure (Awareness and Non-Judgement).

3. Reliability: The SMM would demonstrate acceptable reliability across gender.

4. Convergent validity: The SMM would be moderately positively associated with trait mindfulness.

5. Criterion validity: The SMM would be negatively associated with sexual shame and sexual anxiety, and positively associated with sexual consent beliefs, sexual esteem, body image, self-efficacy, and disclosure to parents, above and beyond the associations of trait mindfulness.

\section{Methods}

\subsection{Participants and procedures}

The Healthy Sexuality Project (HSP) was initiated to establish quality measurement for U.S. adolescent healthy sexuality. We partnered with Qualtrics, who administered a 20-min survey to approximately 2000 adolescents (half boys/girls; $1 / 3$ low, medium, and high income) aged 13-18 (one group 13-15, another 16-18). Participants signed consent forms and were given compensation through Qualtrics that equated to about $\$ 3$ in gift cards. All institutional IRB guidelines were followed.

We used two subsamples for our analyses: a sample which included adolescents with no sexual experience $(n=1006)$ and one which included adolescents with sexual experience $(n=670)$. We asked the participants about their engagement in a number of sexual behaviors: kissing, oral sex, sexual touching, and intercourse. We divided adolescents into two groups: sexually active-those who had engaged in sexual behaviors beyond kissing- and non-sexually active-those who had no sexual experience or who had only engaged in kissing. Kissing is a sexual behavior that is positively associated with relational quality even for the young adolescent, whereas intercourse may be negatively associated with relational quality during young adolescence (Welsh, Haugen, Widman, Darling, \& Grello, 2005). Because of this qualitative difference we chose to include kissing-only adolescents in the non-sexually active group. The subsample without sexual experience only included adolescents who indicated they had never engaged in sexual behavior throughout their lifetime and had never had a sexual partner. In contrast, the subsample of adolescents with sexual experience was constrained to include adolescents who had indicated they had a least one sexual partner in their lifetime; this analytic subsample was composed of 670 adolescents. Non-sexually active individuals did not complete the sexual mindfulness measures and therefore, they were not used for the analyses to evaluate the SMM. As compared to the structural model ( $n=670)$, the analytic sample of adolescents is smaller $(n=554)$ in the exploratory factor analyses, confirmatory factor analyses, and invariance testing because of how differences in how missing data is handled in these procedures. Sample description and Cronbach's alphas based on sample of 670 adolescents. Table 1 illustrates demographic characteristics of both subsamples side by side.

\subsection{Measures}

Where relevant, alphas are reported for both the sample with sexual experience (abbreviated as WSE) and the sample with no sexual experience (abbreviated NSE). If no abbreviation is given, alphas are for the sample with sexual experience.

Lifetime sexual partners. This item assessed participants' lifetime sexual partners. Participants responded to the question "In your lifetime, how many people have you had sex with" by selecting one of the following response options " $1=$ (Free response), 2 = I prefer not to answer, 3 = I doi know what this means."

Intercourse partners in last 6 months. This item assessed participants' number of sexual intercourse partners in the past 6 months. Participants responded to the question "Altogether in the past six months, with how many sexual partners have you had sexual intercourse." Available responses included " 1 = Free response, $2=$ I don't know what this means, $3=$ I prefer not to say."

Parental income. This item assessed the perception children had of their parents' income. Participants responded to the question "Compared to other families, how would you say yours compares." Available response options included " $1=$ My family has much 
Table 1

Demographic characteristics of subsamples.

\begin{tabular}{|c|c|c|c|c|}
\hline \multirow[b]{2}{*}{ Age } & \multirow[t]{2}{*}{$\begin{array}{l}\text { With Sexual } \\
\text { Experience }(n=1006)\end{array}$} & \multirow[t]{2}{*}{$\begin{array}{l}\text { No Sexual } \\
\text { Experience }(n=670)\end{array}$} & \multicolumn{2}{|c|}{$\begin{array}{l}\text { Difference Test } \\
\text { Results ( } \chi^{2} \text { or } t \text {-test) }\end{array}$} \\
\hline & & & $\mathrm{t}(1674)=$ & $-19.61^{* * *}$ \\
\hline Mean & 17.11 & 15.59 & & \\
\hline Standard deviation & 1.28 & 1.71 & & \\
\hline \multicolumn{5}{|l|}{ Gender } \\
\hline Female & $54 \%$ & $41 \%$ & $\chi 2(1)=$ & $30.43^{* * *}$ \\
\hline Male & $41 \%$ & $54 \%$ & $\chi^{2(1)}=$ & $26.52^{* * *}$ \\
\hline Transgender & $2 \%$ & $3 \%$ & $\chi 2(1)=$ & 1.38 \\
\hline Queer/gender non-conforming & $3 \%$ & $3 \%$ & $\chi^{2(1)}=$ & $<.01$ \\
\hline \multicolumn{5}{|l|}{ Race } \\
\hline African American & $12 \%$ & $16 \%$ & $\chi 2(1)=$ & 3.80 \\
\hline Asian American & $2 \%$ & $13 \%$ & $\chi^{2(1)}=$ & $30.85^{* * *}$ \\
\hline Latino & $14 \%$ & $13 \%$ & $\chi^{2(1)}=$ & .32 \\
\hline Caucasian & $58 \%$ & $50 \%$ & $\chi^{2(1)}=$ & $9.85^{* *}$ \\
\hline Native American & $2 \%$ & $0 \%$ & $\chi 2(1)=$ & $8.26^{* *}$ \\
\hline Mixed/other & $1 \%$ & $9 \%$ & $\chi^{2(1)}=$ & .83 \\
\hline Mother's highest education & & & $\mathrm{t}(1623)=$ & $4.50^{* * *}$ \\
\hline High school/GED or less & $33 \%$ & $24 \%$ & & \\
\hline Some college/vocational degree & $15 \%$ & $36 \%$ & & \\
\hline Associate degree & $6 \%$ & $6 \%$ & & \\
\hline College graduate & $29 \%$ & $41 \%$ & & \\
\hline Advanced degree (e.g., MBA, PhD, law medical) & $14 \%$ & $18 \%$ & & \\
\hline Father's highest education & & & $\mathrm{t}(1561)=$ & $5.40^{* * *}$ \\
\hline High school/GED or less & $43 \%$ & $31 \%$ & & \\
\hline Some college/vocational degree & $14 \%$ & $14 \%$ & & \\
\hline Associate degree & $5 \%$ & $5 \%$ & & \\
\hline College graduate & $20 \%$ & $34 \%$ & & \\
\hline Advanced degree (e.g., MBA, PhD, law medical) & $13 \%$ & $16 \%$ & & \\
\hline Income & & & $\mathrm{t}(1674)=$ & $2.61 * *$ \\
\hline "much less money than other families" & $6 \%$ & $3 \%$ & & \\
\hline "less than other families" & $30 \%$ & $25 \%$ & & \\
\hline "about the same amount of money as other families" & $43 \%$ & $50 \%$ & & \\
\hline "more money than other families" & $17 \%$ & $20 \%$ & & \\
\hline "much more money than other families" & $4 \%$ & $2 \%$ & & \\
\hline \multicolumn{5}{|l|}{ Sexual Partners } \\
\hline Lifetime median ${ }^{\mathrm{a}}$ & 2 & 0 & $t(1546)=$ & $-14.69^{* * *}$ \\
\hline Lifetime median last 6 months ${ }^{\mathrm{a}}$ & 2 & 0 & $\mathrm{t}(1571)=$ & $-15.07^{* * *}$ \\
\hline
\end{tabular}

Note. ${ }^{* *} p<.001,{ }^{* *} p<.01,{ }^{*} p<.05$.

a Medians instead of means are more representative of these variables as they are skewed toward upper ranges. For reference, in the subsample with sexual experience, mean of lifetime sexual partners is 3.67 ( $S D=7.92$, min $=1$, max $=125$ ) and mean of intercourse partners in last six months $=12.50(S D=26.32, \min =0, \max =180)$.

less money than other families, 2 = My family has less money than other families, 3 = My family has about the same amount of money as other families, $4=$ My family has more money than other families, $5=$ My family has much more money than other families."

Adolescent age. This item assessed the age of adolescent participants. Participants responded to the question "How old are you in years" and were able to provide their age as a free response.

Race. This item assessed the race of the participants. Participants responded to the question "Your race or ethnic group is." Participants selected one of the following response options, "1 = African American (Black), 2 = Asian-American, $3=$ Latino (Mexican American, Puerto Rican, Cuban, etc.), $4=$ Caucasian (White), $5=$ Native American, $6=$ Mixed/Biracial, $7=$ Other (free response)."

Sex. This item assessed participants' assigned sex at birth. Participants responded to the question "What sex were you assigned at birth, on your original birth certificate," answering either " 1 = Male or 2 = Female."

Gender. This item assessed participants' gender identity. Participants responded to the question "With which gender identity do you most identify?" Available responses included " $1=$ Female, $2=$ Male, $3=$ Transgender Female, $4=$ Transgender Male, 5 = Gender Queer/Non-conforming, 6 = Not listed (free response), 7 = Prefer not to answer."

Sexual Attitudes: sexual shame and consent. Sexual shame was assessed using three items from the Kyle Inventory of Sexual Shame (KISS; Kyle, 2013). The participants were asked to rate their agreement with three statements reflective of sexual shame using a Likert scale of 1 (strongly disagree) to 6 (strongly agree), with higher scores reflecting more personal shame regarding sexuality. Sample items included "I think people would look down on me if they knew about my sexual experiences," and "I feel ashamed about having sexual fantasies." The adolescents' personal beliefs regarding sexual consent were assessed using a reduced version of The Sexual Consent Scale-Revised (SCS-R; Humphreys \& Brousseau, 2010). Adolescents rated their agreement with three statements about sexual consent using Likert scale of 1 (strongly disagree) to 5 (strongly agree). Higher scores reflect a greater belief in sexual 
consent. A sample item is "I feel that sexual consent should always be obtained before the start of any sexual activity." The alphas were shame $\alpha=0.68$; consent: WSE $\alpha=0.80$; NSE $\alpha=0.86$.

Sexual anxiety and sexual esteem. Sexual esteem and anxiety were measured using six items (Rostosky, Dekhtyar, Cupp, \& Anderman, 2008). Participants responded to three statements reflective of sexual esteem and three statements reflective of sexual anxiety using a Likert scale of 1 (not at all like me) to 5 (completely like me). Higher values reflected higher levels of sexual esteem and anxiety, respectively. A sample item for sexual esteem is "I am pleased with how I handle my own sexual tendencies and behaviors," while a sample item for sexual anxiety includes "I feel anxious when I think about the sexual aspects of my life." The alphas were sexual anxiety $\alpha=0.78$; sexual esteem $\alpha=0.83$.

Body Esteem. Body esteem was measured using a shortened version of the Body Esteem Scale for Adolescents and Adults (Mendelson, Mendelson \& White, 2001). Respondents rated their agreement to three items using a Likert scale of 1 (strongly disagree) to 5 (strongly agree). A negatively worded item was reverse coded such that higher scores reflected a positive affect with regards to one's appearance. An example item is "I believe that I am a physically attractive person." The alpha was WSE: $\alpha=0.80$; NSE $\alpha=0.78$.

General Self-Efficacy. Adolescents reported their general self-efficacy using a reduced version of the New General Self-Efficacy Scale (Chen, Gully, \& Eden, 2001). Respondents rated four items using a Likert scale of 1 (strongly disagree) to 5 (strongly agree), with higher scores reflecting higher self-efficacy. An example item is "I will be able to successfully overcome many challenges." The alpha was WSE: $\alpha=0.87$; NSE $\alpha=0.87$.

Disclosure to Parents About Sexuality. Adolescents reported on their disclosure to their parents about their own sexuality using parallel forms of five items adapted from the Self-Disclosure Index (Miller, Berg, \& Archer, 1983). The Self-Disclosure Index was adapted to be specific to a child's disclosure to their parents about sexuality. In addition, three items were created for this study. Adolescents used a Likert scale of 1 (never) to 5 (always), with higher scores reflecting more frequent disclosure or secret keeping, respectively, for example, "Talk to my parent about my sexual relationships with other people." A sample secrecy item is "Keep secrets from my parent about my sexual behavior with others." Adolescents reported for both their fathers and mothers. The alphas for disclosure to both fathers was WSE: $\alpha=.89$; NSE $\alpha=0.88$ and mothers was WSE: $\alpha=0.90$; NSE $\alpha=0.88$.

Mindfulness. Adolescents reported on their trait mindfulness using three items from the short form of the Mindful Attention Awareness Scale (Osman, Lamis, Bagge, Freedenthal, \& Barnes, 2016). Respondents rated how frequently various statements about mindfulness reflected their experiences using a Likert scale of 6 (almost never) to 1 (almost always), with higher scores reflecting higher mindfulness. A sample item is "I run through activities without being really attentive to them." The alpha was WSE: $\alpha=0.77$; NSE $\alpha=0.78$.

Sexual Mindfulness. Sexual mindfulness was measured using seven items developed by Blinded for Review, (2019). Participants responded to four statements relating to the awareness aspect of sexual mindfulness and three statements relating to the nonjudgment aspect of sexual mindfulness using a Likert scale of 1 (never or rarely True) to 5 (very often or always true). Negative items were reverse scored such that higher scores reflected greater sexual mindfulness. A sample item for awareness is "I pay attention to sexual sensations," and a sample item for non-judgment is "During sex, I sometimes get distracted by evaluating myself or my partner." The alphas were sexual mindfulness aware $\alpha=0.82$; non-judgment $\alpha=0.76$.

\subsection{Analysis}

Assumptions and data preparation with subsample with no sexual experience. The assumptions of multiple linear regression were tested in Stata (Version 15, StataCorp, 2017) and corrected for when necessary, as described below, prior to running the structural equation model in Mplus (Version 8; Muthén \& Muthén, 1998-2017) predicting adolescent outcomes in the subsample with no sexual experience. The assumption of independence was satisfied as observations were not linked. The assumption of homoscedasticity was violated as indicated by Breusch-Pagan testing; therefore, the Huber-White sandwich estimator (robust estimation) was utilized in the structural model. Testing indicated that the assumption of linearity was satisfied. The assumption of no collinearity was considered satisfied as variance inflation factors scores (VIF) were in appropriate ranges (max VIF $=1.30$, mean VIF $=1.21$ ). Lastly, the assumption of normally distributed errors was tested through visual inspection of histograms and Q-Q plots and inspection of skewness and kurtosis values of residuals; based on these inspections, this assumption was considered satisfied except when pertaining to sexual consent as an outcome. Skewness and kurtosis of residuals of the regression model predicting sexual consent were respectively -0.193 and 7.01 . Follow up inspection comparing regression models predicting sexual consent with and without observations that surpassed appropriate Cook's distance values indicated no substantive difference in terms of trait mindfulness as a predictor (our key variable of interest) when it came to standard errors and effect sizes. After preforming this follow-up testing, and, understanding that our sample size was relatively large $(n=1006)$ and more robust to violations of the assumption of normally distributed errors as compared to smaller samples (Lumley, Diehr, Emerson, \& Chen, 2002), we proceeded with caution and constructed our structural model in Mplus.

Sexual mindfulness variables were not included as independent variables, sexual shame, sexual anxiety, and sexual esteem variables were not included as dependent variables, and number of sexual partner variables were not included as controls. We also did not specify in Mplus that any means should be estimated for missing data in terms of any variables.

Assumptions and data preparation with subsample with sexual experience. Exploratory factor analysis (EFA), calculation of Cronbach's alphas (Table 2), and data preparation were conducted in Stata on the subsample with sexual experience. Confirmatory factor analysis (CFA) and the structural equation model predicting adolescent outcomes were conducted in Mplus. EFA was performed on the seven sexual mindfulness items using principle axis factoring, promax rotation, and Kaiser normalization (Matsunaga, 
Table 2

Adolescent latent variable estimated means, estimated standard deviations, and correlations for subsample with No sexual experience.

\begin{tabular}{|c|c|c|c|c|c|c|c|c|}
\hline & & M & SD & 1 & 2 & 3 & 4 & 5 \\
\hline 1 & Mindfulness & .00 & .91 & - & & & & \\
\hline 2 & Self-efficacy & .83 & .74 & $.15^{* * *}$ & - & & & \\
\hline 3 & Body esteem & 1.24 & .87 & $.28 * * *$ & $.46^{* * *}$ & - & & \\
\hline 4 & Consent Beliefs & .42 & .75 & $-.09 *$ & $.21^{* * *}$ & -.07 & - & \\
\hline 5 & S-DISC to mother & -.84 & 1.29 & $.25^{* * *}$ & $.06^{*}$ & $.18^{* * *}$ & $-.14^{* * *}$ & - \\
\hline 6 & S-DISC to father & -.68 & 1.34 & $.22^{* * *}$ & $.08^{*}$ & $.21 * * *$ & $-.18^{* * * *}$ & $.95^{* * *}$ \\
\hline
\end{tabular}

Note. $* p<.05, * * p<.01, * * * p<.001$; "S-DISC" short for sexual disclosure.

2010) (Table 2). CFA was performed on the two subscales of sexual mindfulness with the test being performed on both subscales simultaneously (Table 2). For both EFA and CFA $n=554$.

Prior to running the structural equation model in Mplus predicting adolescent outcomes in the subsample with sexual experience, the Assumptions of multiple linear regression were tested in Stata and corrected for when necessary, as described below. The assumption of independence was satisfied as observations were not linked. The assumption of homoscedasticity was violated as indicated by Breusch-Pagan testing; therefore, the Huber-White sandwich estimator (robust estimation) was utilized in the structural model. Regarding the assumption of linearity, testing indicated that trait mindfulness and sexual-mindfulness-non-judging had non-linear (quadratic) relationships with dependent variables; accordingly, a squared term of each of these two variables was included in the final structural model and we considered the linearity assumption satisfied. The assumption of no collinearity was considered satisfied as variance inflation factors scores (VIF) were in appropriate ranges (max VIF $=1.27$, mean VIF $=1.22$ ). Lastly, the assumption of normally distributed errors was tested for through visual inspection of histograms and Q-Q plots and inspection of skewness and kurtosis values of residuals; based on these inspections, this assumption was considered satisfied.

The structural equation model predicting adolescent outcomes included latent variables for all dependent variables as well as trait mindfulness and its squared term, sexual-mindfulness-awareness and its squared term, and sexual-mindfulness-non-judging (see Table 3 for univariate and bivariate statistics of latent variables). Maximum-likelihood-robust was used as the estimation method. In Mplus, we specified that means should be estimated for missing data in terms of observed sexual mindfulness items (both awareness and non-judging) and the log of lifetime sexual partners. These variables were missing-completely-at-random according to Little's MCAR test $\left(\chi^{2}(8)=13.293, p=.102\right)$. For the other variables, the default usage of missing data theory in Mplus was used. The model controlled for the demographic variables of parental income, parent education levels, child age, race, and gender. Additionally, the model controlled for the natural log of lifetime sexual partners and the natural log of sexual intercourse partners in the last six months. Natural $\log$ transformations were performed to account for extremes in the original scores of these variables.

\section{Results}

\subsection{H1: adolescent sample with no sexual experience}

Hypothesis 1, that "Trait mindfulness would be positively associated with sexual consent beliefs, body-image, self-efficacy, and disclosure to parents" was confirmed (Tables $2-3)$. The model fit the data well $\left(\chi^{2}(290)=508.893, p<.001\right.$, CFI $=0.981$, RMSEA $=0.027$, SRMR $=0.024)$. Further, trait mindfulness was significantly and negatively related to consent beliefs $(\beta=-0.08, p<.05)$ and significantly and positively related to self-efficacy $(\beta=0.09, p<.05)$, body esteem $(\beta=0.20, p<.001)$, sexual disclosure to a

Table 3

Standardized results of structural model with subsample of adolescents with No sexual experience.

\begin{tabular}{|c|c|c|c|c|c|}
\hline & Consent beliefs & Self-efficacy & Body esteem & Sexual disclosure to mother & Sexual disclosure to father \\
\hline Mindfulness & $-.08^{*}$ & $.09 *$ & $.20 * * *$ & $.23^{* * *}$ & $.20 * * *$ \\
\hline Parental income & .03 & $.15^{* * *}$ & $.20 * * *$ & .04 & .05 \\
\hline Parent 1 education & .02 & .04 & .08 & .06 & $.09 *$ \\
\hline Parent 2 education & -.01 & -.05 & -.01 & -.05 & -.06 \\
\hline Child age & .06 & .06 & .04 & $-.08 *$ & $-.08 *$ \\
\hline African American & $-.10 *$ & $.11 * *$ & $.17^{* * *}$ & .03 & .05 \\
\hline Asian American & -.05 & -.06 & .01 & -.03 & -.03 \\
\hline Latino & -.04 & .05 & .01 & -.02 & -.01 \\
\hline Native American & $.03 *$ & .03 & $-.05^{* * *}$ & -.05 & -.04 \\
\hline Mixed or other race & .00 & .02 & -.02 & -.07 & -.05 \\
\hline Male & -.05 & .07 & $.13^{* * *}$ & -.04 & .01 \\
\hline Transgender & -.01 & $-.14^{* *}$ & $-.15^{* * *}$ & $-.07 *$ & $-.06 *$ \\
\hline Queer/non-conforming & $.08 * * *$ & -.07 & -.06 & .03 & .03 \\
\hline$R^{2}$ & .04 & .09 & .22 & .09 & .08 \\
\hline
\end{tabular}

Note. ${ }^{*} p<.05,{ }^{* *} p<.01,{ }^{* *} p<.001$; White comparison group for race; female comparison group for gender, $n=1006$. 


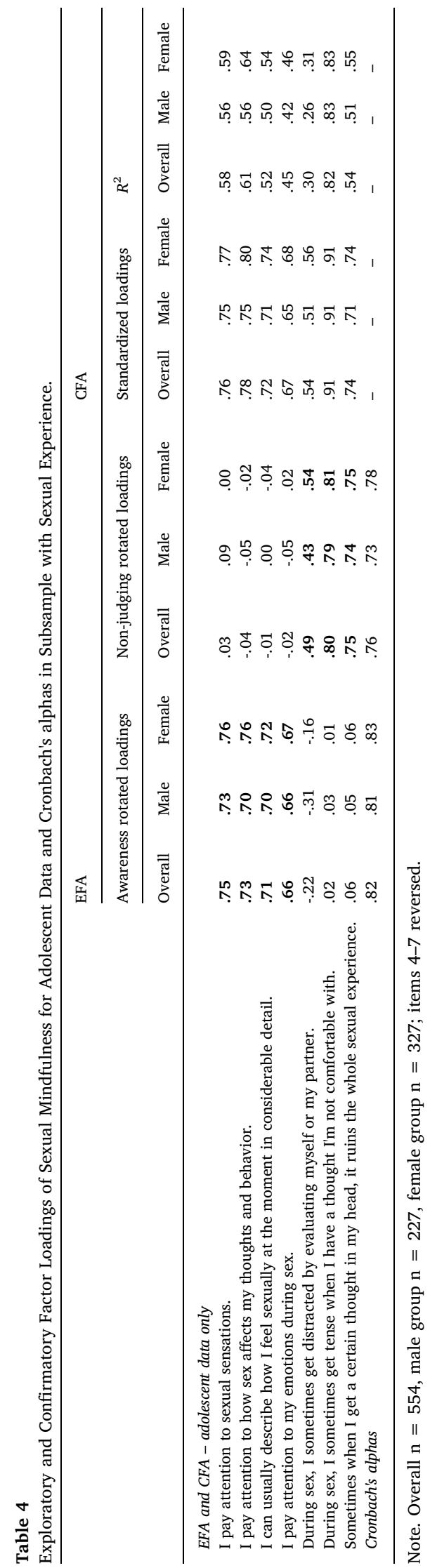


Table 5

Adolescent latent variable estimated means, estimated standard deviations, and correlations for subsample with sexual experience.

\begin{tabular}{|c|c|c|c|c|c|c|c|c|c|c|c|c|}
\hline & & 1 & 2 & 3 & 4 & 5 & 6 & 7 & 8 & 9 & 10 & 11 \\
\hline 1 & SM - awareness & - & $-.31 * * *$ & .04 & $.45^{* * *}$ & -.03 & $.22 * *$ & $.17^{*}$ & $-.26 * * *$ & $.37 * * *$ & -.04 & -.09 \\
\hline 2 & SM - non-judging & $-.24 * *$ & - & $.28^{* * * *}$ & .09 & $-.36^{* * * *}$ & .08 & $.26^{* * *}$ & $-.37 * * *$ & $-.17^{*}$ & .10 & .09 \\
\hline 3 & Mindfulness & .03 & .10 & - & $.23^{* * *}$ & $-.30 * * *$ & $.28 * * *$ & $.30 * * *$ & $-.37 * * *$ & -.10 & .09 & $.21 * *$ \\
\hline 4 & Sexual esteem & $.27^{* * *}$ & .10 & .08 & - & $-.31 * * *$ & $.33^{* * *}$ & $.35^{* * *}$ & $-.44 * * *$ & .11 & $.12^{*}$ & .02 \\
\hline 5 & Sexual anxiety & .07 & $-.39 * * *$ & $-.19 * *$ & $-.17^{*}$ & - & $-.30 * * *$ & $-.39 * * *$ & $.60 * * *$ & .00 & -.05 & -.01 \\
\hline 6 & Self-efficacy & .13 & .15 & .13 & $.40 * * *$ & $-.17^{*}$ & - & $.47 * * *$ & $-.35^{* * *}$ & .06 & .07 & .04 \\
\hline 7 & Body esteem & .00 & $.19^{*}$ & $.25^{* *}$ & $.37 * * *$ & $-.25 * * *$ & $.52^{* * *}$ & - & $-.52 * * *$ & $-.15^{*}$ & .09 & .08 \\
\hline 8 & Sexual shame & .06 & $-.40 * * *$ & $-.23 * *$ & $-.34 * * *$ & $.67 * * *$ & $-.17^{*}$ & $-.36^{* * *}$ & - & .01 & -.07 & -.04 \\
\hline 9 & Consent beliefs & $.25 * *$ & .05 & .02 & $.15^{*}$ & $-.15^{*}$ & .13 & .06 & -.09 & - & $-.15^{*}$ & $-.18^{* * *}$ \\
\hline 10 & S-DISC to mother & -.06 & -.10 & .08 & .08 & .08 & -.07 & $.15^{*}$ & .02 & -.08 & - & $.80 * * *$ \\
\hline \multirow[t]{5}{*}{11} & S-DISC to father & -.09 & -.08 & $.16^{*}$ & .11 & .05 & .01 & $.20 * *$ & .00 & -.08 & $.94 * * *$ & - \\
\hline & Mean (male) & -.09 & -.25 & -.24 & .07 & .02 & -.07 & -.24 & .25 & .22 & -.16 & -.33 \\
\hline & Mean (female) & .00 & .00 & .00 & .00 & .00 & .00 & .00 & .00 & .00 & .00 & .00 \\
\hline & SD (male) & .85 & .71 & .81 & .92 & .96 & .75 & 1.00 & .90 & .64 & 1.12 & 1.16 \\
\hline & SD (female) & .78 & .65 & .87 & .89 & .91 & .72 & .90 & .85 & .73 & 1.23 & 1.29 \\
\hline
\end{tabular}

Note. ${ }^{*} p<.05, * * p<.01, * * p<.001$; "SM" short for sexual mindfulness, "S-DISC" short for sexual disclosure; estimates for male group above diagonal, estimates for female group below diagonal.

mother figure $(\beta=0.23, p<.001)$, and sexual disclosure to a father figure $(\beta=0.20, p<.001)$.

\subsection{H2 and H3: construct validity and reliability}

Hypothesis 2 that "The SMM would maintain a two-factor structure (Awareness and Non-Judgement) and Hypothesis 3 that "The SMM would demonstrate acceptable reliability across gender" were confirmed. The result of exploratory factor analysis was a two-factor solution and the result of the confirmatory factor analysis was adequate standardized factor loadings $(>0.50)$ across the two factors as well as adequate model fit $\left(\chi^{2}(13)=49.071, p<.001, \mathrm{CFI}=0.972\right.$, RMSEA $=0.071$, SRMR $\left.=0.058\right)($ Table 4). Further, both sub-constructs of the SMM demonstrated acceptable reliability across gender with Cronbach's alphas being higher than 0.70 .

\subsection{H4: convergent validity}

Hypothesis 4, that "The SMM would be moderately positively associated with trait mindfulness" was partially confirmed. Sexual mindfulness awareness was not significantly associated with trait mindfulness $(r=0.03, p=.68)$. However, sexual mindfulness nonjudging was significantly and positively associated with trait mindfulness $(r=0.22, p<.001)$ (Table 5). Thus, there is partial evidence that the SMM factors were associated with but also distinct from trait mindfulness.

\subsection{H5: criterion validity}

Hypothesis 5, that "The SMM would be negatively associated with sexual shame and sexual anxiety, and positively associated with sexual consent beliefs, body image, self-efficacy, disclosure to parents, and sexual esteem above and beyond the associations of trait mindfulness" was confirmed (Table 6). Either sexual mindfulness awareness (SMA), the squared term of sexual mindfulness awareness (SMASQ), or sexual mindfulness non-judging (SMNJ) was significantly related to the hypothesized constructs with adequate model fit $\left(\chi^{2}\right.$ $(886)=1419.407, p<.001$, CFI $=962$, RMSEA $=030$, SRMR $=035)$. These associations existed after accounting for trait mindfulness and control variables.

Specifically, sexual shame was significantly and negatively related to SMA $(\beta=-0.21, p<.01)$ and SMNJ ( $\beta=-0.40$, $p<.001)$ but not significantly related to SMASQ $(\beta=-0.01, p=.85)$. Consent beliefs were significantly and positively related to SMA $(\beta=0.35, p<.001)$ and significantly and negatively related to SMASQ $(\beta=-0.18, p<.05)$ but not significantly related to $\operatorname{SMNJ}(\beta=0.06, p=.30)$. Sexual anxiety was significantly and negatively related to SMNJ $(\beta=-0.34, p<.001)$ but not significantly related to SMA $(\beta=-0.03, p=.65)$ and SMASQ $(\beta=0.01, p=.895)$. Sexual esteem was significantly and positively related to SMA $(\beta=0.43, p<.001)$ and SMNJ $(\beta=0.18, p<.01)$ but was not significantly related to SMASQ $(\beta=-0.02, p=$ .64). Body esteem was significantly and positively related to SMA $(\beta=0.15, p<.01)$ and SMNJ $(\beta=0.21, p<.001)$ but not significantly related to SMASQ $(\beta<0.01, p=.98)$. Self-efficacy was significantly and positively related to SMA $(\beta=0.24$, $p<.001)$ and SMNJ $(\beta=0.12, p<.05)$ but not SMASQ $(\beta<0.01, p=.950)$. Sexual disclosure to a mother figure was significantly and positively related to SMASQ $(\beta=0.14, p<.01)$ but not significantly related to SMA $(\beta=-0.01, p=.87)$ or SMNJ ( $\beta<0.01$, $p=.96)$. Sexual disclosure to a father figure was significantly and positively related to SMASQ $(\beta=0.12, p<.01)$ but not significantly related to SMA $(\beta=-0.09, p=.21)$ or SMNJ $(\beta<-0.04, p=.49)$.

\section{Discussion}

Mindfulness and sexual mindfulness may provide tools that empower adolescents to maintain healthier boundaries, more positive 
Table 6

Standardized results of structural model assessing influence of adolescent sexual mindfulness on adolescent outcomes in subsample with sexual experience.

\begin{tabular}{|c|c|c|c|c|c|c|c|c|}
\hline & $\begin{array}{l}\text { Sexual } \\
\text { shame }\end{array}$ & $\begin{array}{l}\text { Consent } \\
\text { beliefs }\end{array}$ & $\begin{array}{l}\text { Sexual } \\
\text { anxiety }\end{array}$ & $\begin{array}{l}\text { Sexual } \\
\text { esteem }\end{array}$ & $\begin{array}{l}\text { Body } \\
\text { esteem }\end{array}$ & Self-efficacy & $\begin{array}{l}\text { Sexual disclosure } \\
\text { to mother }\end{array}$ & $\begin{array}{l}\text { Sexual disclosure } \\
\text { to father }\end{array}$ \\
\hline Mindfulness & $-.20 * *$ & -.03 & $-.20^{* * *}$ & $.11^{*}$ & $.20^{* * * *}$ & $.15^{* *}$ & $.12^{*}$ & $.23^{* * *}$ \\
\hline Mindfulness squared & .06 & $.10^{*}$ & .10 & .03 & .06 & .06 & .09 & $.12^{*}$ \\
\hline $\begin{array}{l}\text { Sexual mindfulness - } \\
\text { awareness }\end{array}$ & $-.21^{* *}$ & $.35^{* * *}$ & -.03 & $.43^{* * *}$ & $.15^{* *}$ & $.24^{* * *}$ & -.01 & -.09 \\
\hline $\begin{array}{l}\text { Sexual mindfulness - } \\
\text { awareness squared }\end{array}$ & -.01 & $-.18^{*}$ & .01 & -.02 & .00 & .00 & $.14^{* *}$ & $.12^{* *}$ \\
\hline $\begin{array}{l}\text { Sexual mindfulness - non- } \\
\text { judging }\end{array}$ & $-.40 * * *$ & .06 & $-.34^{* * *}$ & $.18^{* *}$ & $.21^{* * *}$ & $.12^{*}$ & .00 & -.04 \\
\hline Log of lifetime sexual partners & .04 & -.06 & .01 & -.04 & .05 & -.06 & .07 & .08 \\
\hline $\begin{array}{l}\text { Log of intercourse partners in } \\
\text { last } 6 \text { months }\end{array}$ & -.02 & -.01 & -.07 & .06 & .05 & .01 & .02 & .00 \\
\hline Parental income & $-.13^{* *}$ & -.09 & -.01 & .05 & $.25^{* * *}$ & .02 & .06 & .06 \\
\hline Parent 1 education & .03 & .04 & -.01 & .03 & -.02 & .05 & .05 & .04 \\
\hline Parent 2 education & .00 & .04 & $.12^{*}$ & -.05 & .06 & -.03 & -.08 & -.05 \\
\hline Child age & -.09 & .05 & $-.12 * *$ & .07 & .05 & $.11^{*}$ & -.03 & -.02 \\
\hline African American & -.04 & -.08 & $.11^{*}$ & .03 & $.09^{*}$ & .05 & -.05 & -.04 \\
\hline Asian American & .06 & -.09 & $.13^{* *}$ & $-.11^{*}$ & -.04 & -.09 & $-.09 *$ & $-.09 *$ \\
\hline Latino & -.03 & -.03 & .06 & -.01 & -.01 & .01 & -.04 & .00 \\
\hline Native American & -.01 & -.01 & .05 & .05 & .01 & .02 & .00 & -.01 \\
\hline Mixed or other race & .01 & -.05 & $.10^{*}$ & -.05 & .03 & .04 & $-.10 *$ & -.04 \\
\hline Male & -.07 & $-.13^{* *}$ & -.01 & -.08 & .04 & -.03 & .03 & $.09 *$ \\
\hline Transgender & .04 & $.04 *$ & -.02 & -.08 & $-.13^{* *}$ & -.07 & -.04 & .00 \\
\hline Queer/non-conforming & .04 & .02 & -.02 & .03 & $-.08 *$ & $-.16^{* *}$ & .01 & .02 \\
\hline$R^{2}$ & .32 & .26 & .27 & .25 & .27 & .16 & .10 & .14 \\
\hline
\end{tabular}

Note. ${ }^{*} p<.05,{ }^{* *} p<.01,{ }^{* *} p<.001$; White comparison group for race; female comparison group for gender, $n=670$.

self-evaluations, and be more intentional in the sexual experiences that they choose to have. In addition to finding positive associations between trait mindfulness and self-efficacy, body image, and disclosure to both mothers and fathers, this study demonstrated that sexual mindfulness is a unique construct that can be reliably measured in adolescence.

\subsection{Trait mindfulness and adolescents}

Mindful adolescents who reported no sexual experience also showed links to the positive outcomes of self-efficacy, body-esteem, and disclosure of sexual issues to both their fathers and mothers. Because adolescents are prone to self-critical feeling and disconnection (Jacobs et al., 2002, https://link.springer.com/article/10.1007/s10826-013-9830-2), these findings are particularly encouraging as trait mindfulness may provide a buffer for adolescents who struggle with feelings of belonging or worth or who simply do not feel ready for sexual activity (Pepping, O'Donovan, \& Davis, 2013; Tan \& Martin, 2016). Adolescent development in these skills is salient as adolescents engage in more complex thought processes, move toward greater independence, work toward resolving internal concerns with appearance, and parental influence (Spano, 2004). Parents who encourage mindfulness may gain insight to their child as the child is more disclosing about private information (Lippold et al., 2015). Interestingly these adolescents showed a slightly negative association with consent. This finding should be interpreted with caution as it may be that mindful adolescents, who had no sexual experience, may be less attuned to the need to gain consent. In contrast, research in adult populations indicated mindfulness was positively associated with more ethical behaviors (Ruedy \& Schweitzer, 2010; Shapiro, Jazaieri, \& Goldin, 2012). Additionally, within the sexually active sample in this study, sexually mindful adolescents showed positive associations with the endorsement of consent. Issues of adolescent consent should be examined more carefully in future research.

\subsection{Sexual mindfulness and adolescents}

Evaluating the state of adolescents' mindfulness during a sexual experience may be useful for a number of reasons. Adolescence is a challenging developmental stage and for adolescents who engage in sex, it may present additional complexities (Haydon et al., 2012). Much of adolescent research focuses on adolescent sexual activity prevalence and timing (Haydon et al., 2012). This study examines the intentionality of adolescents' sexual experience. Adolescents are often highly self-critical and may feel alone or disconnected (Jacobs et al., 2002, https://link.springer.com/article/10.1007/s10826-013-9830-2). However, sexuality can also be a positive experience, particularly, if adolescents slow their thoughts and remain present and aware. Mindful adolescents may make more purposeful decisions and formulate better attitudes about themselves, their skills, and their sexual experiences, which may result in more intentional behavior.

No previous research has evaluated adolescents' mindfulness during sexual experiences. In the current work we found that adolescent sexual mindfulness is not only a measurable construct but, for those adolescents who had engaged in sexual activity, 
sexual mindfulness is associated with a host of positive adolescent outcomes. This connection to positive adolescent outcomes is consistent with research that indicates that mindfulness creates an openness and sensitivity to the nuanced responses of an individual's emotions and physical responses (Teper, Segal, \& Inzlicht, 2013). Adolescence is a time of development in which boys and girls may experience heightened self-critical feelings, disconnection (Jacobs et al., 2002, https://link.springer.com/article/10.1007/ s10826-013-9830-2), and impulsive tendencies (Whelan et al., 2012). Mindfulness may provide adolescents with the space to slow down their thought process and give more intentional responses. In particular, sexual awareness and non-judgment may provide a mechanism for attunement or openness to the subtle changes in the individual's state of mind or surrounding environment in a curious, non-judgmental way (Teper et al., 2013).

Our finding that adolescent trait mindfulness and sexual mindful awareness was associated with disclosure to parents is of particular importance. Research consistently has indicated that parent-child communication about sex is protective against risky adolescent sexual behavior (Widman, Choukas-Bradley, Noar, Nesi, \& Garrett, 2016). As adolescents slow their thoughts and are more intentional, they also reported talking to their parents more than adolescents who were less mindful. Adolescent disclosure provides an environment wherein parents and children may be able to discuss the meaning of sexuality and guidelines for healthy romantic and sexual relationships.

Sexual mindfulness may also discourage constant rumination that creates anxiety and/or harsh self-evaluations. This study demonstrated that not only trait mindfulness, but the ability to be mindful in a sexual context, is associated with healthy adolescent outcomes. That is, the ability to be aware and avoid judging oneself during sexual experiences is uniquely associated with positive adolescent outcomes. Consequently, sexual mindfulness may be particularly useful in adolescent populations who are in the process of developing attitudes, behavioral and cognitive patterns (Kar et al., 2015), which are especially salient skills within this time of sexual development.

The findings indicated no significant gender differences in sexual mindfulness. The sexual mindfulness constructs of awareness and non-judgment showed similar loadings for both adolescent girls and boys. Although adolescent girls and boys showed no significant difference in sexual mindful awareness, boys showed higher scores in sexual mindful non-judgment than girls. In adult samples men scored higher on both awareness and non-judgement (Leavitt, Lefkowitz et al., 2019). Future research should examine whether sexual mindful awareness diminishes over time. It may be that as young women are exposed to more objectifying ideas about women's sexual roles, they are less attuned to their own body.

While the finding that sexual mindful awareness was not significantly associated with trait mindfulness was not what we had hypothesized, it is not an unexpected finding. Adolescent sexual awareness may be quite focused at this age and may not be transferable to other areas of their life. In an adult sample, trait mindfulness and sexual mindful awareness were significantly associated (Leavitt, Lefkowitz et al., 2019). However, adolescents may be more aware during a sexual experience than during daily activities because sex is so novel and requires more attention. Additionally, the trait mindfulness measure is a one-facet measure and may not capture multi-dimensions like the sexual mindfulness measure did. Future research could further investigate the associations of a multi-faceted trait mindfulness and sexual mindful awareness.

A last ancillary finding to note is that for adolescents, sexual mindfulness awareness and sexual mindfulness non-judging were negatively related (Table 5). This contradicts findings using adult data where researchers found these constructs were positively associated (Leavitt, Lefkowitz et al., 2019). One explanation is that perhaps adolescents who are more aware may also be more judgmental of the circumstances of the sexual experience, whereas sexually mindful adults are judging the quality of the sexual experience itself. Adolescents may be evaluating themselves more so in terms of if the decision to engage in sex was acceptable, how their parental figure(s) would approve, or if this partner is someone they want to engage in sex with, which may be consistent with previous research that found mindful adolescents may over-identify (Manavipour \& Saeedian, 2016). Future work should investigate this explanation and adjust the non-judging scale for adolescent samples to confirm this.

\subsection{Limitations, future directions, and strengths}

One notable strength is that we used a diverse sample of adolescents to examine the Sexual Mindfulness Measure (SMM) and found that the SMM was a valid and reliable measure. However, despite our inclusion of adolescents who identified as queer or nonconforming, the sample size for this group was small and may require future research to further examine the reliability of the SMM within this population.

A second limitation is that these data were cross-sectional and provided only correlational findings and in no way suggest causation. Future research could evaluate adolescents who are taught mindfulness skills and examine whether an increase in trait mindfulness or sexual mindfulness is linked to improved wellbeing. Additionally, there may be some ambiguity in how adolescents interpreted the question "Have you ever engaged in sexual behavior, besides kissing?" and some adolescents may have considered that engaging in fully clothed kissing that involved body rubbing was "non-sexually active." One additional question asked "how many people have you had sex with." This question was open to interpretation on the part of the respondent. If adolescents interpreted sex to mean any type of sexual behavior and not just intercourse, the number of lifetime partners may be over-estimated.

Lastly, we did not assess, nor expect, that the adolescents in this study were experienced in meditation. Prior mindfulness research has discussed that individuals trained in mindfulness may have more sexual awareness of arousal and desire (Brotto \& Basson, 2014; Brotto et al., 2012). Our participants were not experienced with mindfulness and may have over-estimated their mindfulness when compared to individuals who are more familiar with mindfulness. Assessing mindfulness with inexperienced individuals likely measures awareness of daily mindfulness skills not the more transformative form of meditative mindfulness (Baer et al., 2008). Future research may consider how adolescents with experience meditating differ from adolescents who evaluate their mindfulness levels 
without a knowledgeable understanding of a mindfulness practice (Baer et al., 2008; Nielsen \& Kaszniak, 2006).

Despite these limitations, we found that mindful adolescents who were not sexually active showed positive associations with selfefficacy, healthy body-esteem, and disclosure to parents. Additionally, the SMM may provide an important assessment of how sexually active adolescents' ability to remain aware and non-judgmental during sexual experiences may be positively associated with outcomes such as sexual consent, positive body image, self-efficacy, disclosure to parents, and negatively associated with sexual shame and sexual anxiety. This study is particularly notable in an environment where so many young people report that early sexual experiences may have been forced or coerced (Hawks et al., 2019). As adolescents practice more sexual mindfulness their decisions about sex may become more intentional and less swayed by pressure or circumstance and more tuned to issues of consent. Parents, sex educators, and therapists might consider encouraging a mindful approach to adolescents' daily lives and sexual experiences, which may help adolescents navigate some of the complex issues of adolescence.

\section{Compliance with ethical standards}

All human studies have been approved by the BYU IRB ethics committee and have therefore been performed in accordance with the ethical standards laid down in the 1964 Declaration of Helsinki and its later amendments.

All persons gave their informed consent prior to their inclusion in the study. We include no details that would identify participants.

\section{Declaration of competing interest}

The authors have no conflict of interest.

\section{Appendix A. Supplementary data}

Supplementary data to this article can be found online at https://doi.org/10.1016/j.adolescence.2020.04.008.

\section{References}

Baer, R. A., Smith, G. T., Lykins, E., Button, D., Krietemeyer, J., Sauer, S., ... Williams, J. M. G. (2008). Construct validity of the five facet mindfulness questionnaire in meditating and nonmeditating samples. Assessment, 15, 329-342. https://doi.org/10.1177/1073191107313003.

Barker, M. (2017). Mindfulness in sex therapy. In Z. D. Peterson (Ed.). The wiley handbook of sex therapy (pp. 437-452). Chichester, UK: John Wiley \& Sons Ltd.

Barnes, S., Brown, K. W., Krusemark, E., Campbell, W. K., \& Rogge, R. D. (2007). The role of mindfulness in romantic relationship satisfaction and responses to relationship stress. Journal of Marital and Family Therapy, 33(4), 482-500. https://doi.org/10.1111/j.1752-0606.2007.00033.x.

Biegel, G., Brown, K., Shapiro, S., \& Schubert, C. (2009). Mindfulness-based stress reduction for the treatment of adolescent psychiatric outpatients: A randomized clinical trial. Journal of Clinical and Consulting Psychology, 77(5), 855-866. https://doi.org/10.1037/a0016241.

Bluth, K., \& Blanton, P. W. (2014). Mindfulness and self-compassion: Exploring pathways to adolescent emotional well-being. Journal of Child and Family Studies, 23(7), 1298-1309. https://doi.org/10.1007/s10826-013-9830-2.

Brem, M. J., Shorey, R. C., Anderson, S., \& Stuart, G. L. (2017). Dispositional mindfulness, shame, and compulsive sexual behaviors among men in residential treatment for substance use disorders. Mindfulness, 8(6), 1552-1558. https://doi.org/10.1007/s12671-017-0723-0.

Broderick, P., \& Metz, S. (2009). Learning to breathe: A pilot trial of a mindfulness curriculum for adolescents. Advances in School Mental Health Promotion, 2(1), 35-46. https://doi.org/10.1080/1754730X.2009.9715696.

Brown, K. W., West, A. M., Loverich, T. M., \& Biegel, G. M. (2011). Assessing adolescent mindfulness: Validation of an adapted mindful attention awareness scale in adolescent normative and psychiatric populations. Psychological Assessment, 23(4), 1023-1033. https://doi.org/10.1037/a0021338.

Brown, K. W., \& Ryan, R. M. (2003). The benefits of being present: Mindfulness and its role in psychological well-being. Journal of Personality and Social Psychology, 84(4), 822-848. https://doi.org/10.1037/0022-3514.84.4.822.

Busby, D. M., Leonhardt, N., Leavitt, C. E., \& Hanna-Walker, V. (2020). Challenging the standard model of sexual response: Evidence of a variable male sexual response cycle. Journal of Sex Research. https://doi.org/10.1080/00224499.2019.1705960.

Charoensukmongkol, P., \& Suthatorn, P. (2018). Sales people's trait mindfulness and emotional exhaustion: The mediating roles of optimism, resilience, and selfefficacy. International Journal of Services, Economics and Management, 9(2), 125-142. https://doi.org/10.1504/IJSEM.2018.10017350.

Chen, G., Gully, S. M., \& Eden, D. (2001). Validation of a new general self-efficacy scale. Organizational Research Methods, 4(1), 62-83. https://doi.org/10.1177/ 109442810141004

Dekeyser, M., Raes, F., Leijssen, M., Laysen, S., \& Dewulf, D. (2008). Mindfulness skills and interpersonal behaviour. Personality and Individual Differences, 44(5), 1235-1245. https://doi.org/10.1016/j.paid.2007.11.018.

Dijkstra, P., \& Barelds, D. P. H. (2011). Examining a model of dispositional mindfulness, body comparison, and body satisfaction. Body Image, 8(4), 419-422. https:// doi.org/10.1016/j.bodyim.2011.05.007.

Dunkley, C. R., Goldsmith, K. M., \& Gorzalka, B. B. (2015). The potential role of mindfulness in protecting against sexual insecurities. The Canadian Journal of Human Sexuality, 24(2), 92-103. https://doi.org/10.3138/cjhs.242-A7.

Goldsmith, K., Dunkley, C. R., Dang, S. S., \& Gorzalka, B. B. (2017). Pornography consumption and its association with sexual concerns and expectations among young men and women. The Canadian Journal of Human Sexuality, 26(2), 151-162.

Greco, L. A., Baer, R. A., \& Smith, G. T. (2011). Assessing mindfulness in children and adolescents: Development and validation of the child and adolescent mindfulness measure. Psychological Assessment, 23(3), 606-614. https://doi.org/10.1037/a0022819.

Gustafsson, H., Skoog, T., Davis, P., Kenttä, G., \& Haberl, P. (2015). Mindfulness and its relationship with perceived stress, affect, and burnout in elite junior athletes. Journal of Clinical Sport Psychology, 9(3), 263-281. https://doi.org/10.1123/jcsp.2014-0051.

Fallah, N. (2017). Mindfulness, coping self-efficacy and foreign language anxiety: A mediation analysis. Educational Psychology, 37(6), 745-756. https://doi.org/10. 1080/01443410.2016.1149549.

Halpern, C. T., Waller, M. W., Spriggs, A., \& Hallfors, D. D. (2006). Adolescent predictors of emerging adult sexual patterns. Journal of Adolescent Health, 39(6), 926-936. https://doi.org/10.1016/j.jadohealth.2006.08.005.

Hanley, A. W., Palejwala, M. H., Hanley, R. T., Canto, A. I., \& Garland, E. L. (2015). A failure in mind: Dispositional mindfulness and positive reappraisal as predictors of academic self-efficacy following failure. Personality and Individual Differences, 86, 332-337. https://doi.org/10.1016/j.paid.2015.06.033.

Hawks, L., Woolhandler, S., Himmelstein, D. U., Bor, D. H., Gaffney, A., \& McCormick, D. (2019). Association between forced sexual initiation and health outcomes 
among US women. JAMA Intern Med. Published online September, 16. https://doi.org/10.1001/jamainternmed.2019.3500.

Haydon, A. A., Herring, A. H., \& Halpern, C. T. (2012). Associations between patterns of emerging sexual behavior and young adult reproductive health. Perspectives on Sexual and Reproductive Health, 44(4), 218-227. https://doi.org/10.1363/4421812.

Heath, N. L., Joly, M., \& Carsley, D. (2016). Coping self-efficacy and mindfulness in non-suicidal self-injury. Mindfulness, 7(5), 1132-1141. https://doi.org/10.1007/ s12671-016-0555-3.

Humphreys, T. P., \& Brousseau, M. M. (2010). The sexual consent scale-revised: Development, reliability, and preliminary validity. The Journal of Sex Research, 47(5), 420-428. https://doi.org/10.1080/00224490903151358.

Huppert, F., \& Johnson, D. (2010). A controlled trial of mindfulness training in schools: The importance of practice for an impact of well-being. The Journal of Positive Psychology, 5(4), 264-274. https://doi.org/10.1080/17439761003794148.

Jacobs, J. E., Lanza, S., Osgood, D., Eccles, J. S., \& Wigfield, A. (2002). Changes in children's self-competence and values: Gender and domain differences across grades one through twelve. Child Development, 73(2), 509-527. https://doi.org/10.1111/1467-8624.00421.

Kar, S. K., Choudhury, A., \& Singh, A. P. (2015). Understanding normal development of adolescent sexuality: A bumpy ride. Journal of Human Reproductive Sciences, 8 , $70-74$.

Keye, M. D., \& Pidgeon, A. M. (2013). An investigation of the relationship between resilience, mindfulness, and academic self-efficacy. Open Journal of Social Sciences, 1(6), 1-4. https://doi.org/10.4236/jss.2013.16001.

Kil, H. (2018). Parent dispositional mindfulness and its links to adolescent disclosure, mother-adolescent conflict, and adolescent hostile attribution bias. Toronto, Canada: Doctoral dissertation, University of Toronto. Retrieved from https://tspace.library.utoronto.ca/handle/1807/92128.

Kimmes, J. G., Mallory, A. B., Cameron, C., \& Köse, Ö. (2015). A treatment model for anxiety-related sexual dysfunctions using mindfulness meditation within a sexpositive framework. Sexual and Relationship Therapy, 30(2), 286-296. https://doi.org/10.1080/14681994.2015.1013023.

Klainin-Yobas, P., Ramirez, D., Fernandez, Z., Sarmiento, J., Thanoi, W., Ignacio, J., et al. (2016). Examining the predicting effect of mindfulness on psychological well-being among undergraduate students: A structural equation modelling approach. Personality and Individual Differences, 91, 63-68. https://doi.org/10.1016/j. paid.2015.11.034.

Kyle, S. E. (2013). Identification and treatment of sexual shame: Development of a measurement tool and group therapy protocol (Doctoral dissertation).

Lavender, J. M., Gratz, K. L., \& Anderson, D. A. (2012). Mindfulness, body image, and drive for muscularity in men. Body Image, 9(2), 289-292. https://doi.org/10. 1016/j.bodyim.2011.12.002.

Lazaridou, A., \& Kalogianni, C. (2013). Mindfulness and sexuality. Sexual and Relationship Therapy, 28(1-2), 29-38. https://doi.org/10.1080/14681994.2013.773398.

Leavitt, C. E., Lefkowitz, E. S., Akyil, Y., \& Serduk, K. (2020). A cross-cultural study of midlife relational and sexual health: Comparing Ukraine to the U.S. and Turkey. Sexuality and Culture, 24(3), 649-670. https://doi.org/10.1007/s12119-019-09654-y.

Leavitt, C. E., Lefkowitz, E. S., \& Waterman, E. A. (2019a). The role of sexual mindfulness in sexual, relational, and individual wellbeing. Journal of Sex and Marital Therapy, 45, 497-509.

Leavitt, C. E., Leonhardt, N. D., \& Busby, D. M. (2019b). Different ways to get there: Evidence of a variable female sexual response cycle. The Journal of Sex Research, $56,899-912$

Lippold, M. A., Duncan, L. G., Coatsworth, J. D., Nix, R. L., \& Greenberg, M. T. (2015). Understanding how mindful parenting may be linked to mother-adolescent communication. Journal of Youth and Adolescence, 44(9), 1663-1673. https://doi.org/10.1007/s10964-015-0325-x.

Lumley, T., Diehr, P., Emerson, S., \& Chen, L. (2002). The importance of the normality assumption in large public health data sets. Annual Review of Public Health, 23(1), 151-169. https://doi.org/10.1146/annurev.publhealth.23.100901.140546.

Manavipour, D., \& Saeedian, Y. (2016). The role of self-compassion and control belief about learning in university students' self-efficacy. Journal of Contextual Behavioral Science, 5(2), 121-126. https://doi.org/10.1016/j.jcbs.2016.02.003.

Matsunaga, M. (2010). How to factor-analyze your data right: Do's, don'ts, and how-to's. International Journal of Psychological Research, 3(1), 97-110.

McCabe, M., Althof, S. E., Assalian, P., Chevret-Measson, M., Leiblum, S. R., Simonelli, C., et al. (2010). Psychological and interpersonal dimensions of sexual function and dysfunction. The Journal of Sexual Medicine, 7, 327-336.

McCabe, M. P., \& Taleporos, G. (2003). Sexual esteem, sexual satisfaction, and sexual behavior among people with physical disability. Archives of Sexual Behavior, 32(4), 359-369.

Mendelson, B. K., Mendelson, M. J., \& White, D. R. (2001). Body-esteem scale for adolescents and adults. Journal of Personality Assessment, 76(1), 90-106. https://doi. org/10.1207/S15327752JPA7601_6.

Miller, L. C., Berg, J. H., \& Archer, R. L. (1983). Openers: Individuals who elicit intimate self-disclosure. Journal of Personality and Social Psychology, 44(6), 1234-1244. https://doi.org/10.1037/0022-3514.44.6.1234.

Morton, H., \& Gorzalka, B. B. (2013). Cognitive aspects of sexual functioning: Differences between east asian-canadian and euro-canadian women. Archives of Sexual Behavior, 42(8), 1615-1625. https://doi.org/10.1007/s10508-013-0180-3.

Muthén, L. K., \& Muthén, B. O. (1998-2017). Mplus user's guide (8th ed.). Los Angeles, CA: Muthén \& Muthén.

Newcombe, B. C., \& Weaver, A. D. (2016). Mindfulness, cognitive distraction, and sexual well-being in women. The Canadian Journal of Human Sexuality, 25(2), 99-108. https://doi.org/10.3138/cjhs.252-A3.

Nielsen, L., \& Kaszniak, A. W. (2006). Awareness of subtle emotional feelings: A comparison of long-term meditators and nonmeditators. Emotion, 6, 392-405.

Osman, A., Lamis, D. A., Bagge, C. L., Freedenthal, S., \& Barnes, S. M. (2016). The mindful attention awareness scale: Further examination of dimensionality, reliability, and concurrent validity estimates. Journal of Personality Assessment, 98(2), 189-199. https://doi.org/10.1080/00223891.2015.1095761.

Peters, J. R., Erisman, S. M., Upton, B. T., Baer, R. A., \& Roemer, L. (2011). A preliminary investigation of the relationships between dispositional mindfulness and impulsivity. Mindfulness, 2(4), 228-235.

Pepping, C. A., Cronin, T. J., Lyons, A., \& Caldwell, J. G. (2018). The effects of mindfulness on sexual outcomes: The role of emotion regulation. Archives of Sexual Behavior, 47, 1601-1612. https://doi.org/10.1007/s1050.

Pepping, C. A., O'Donovan, A., \& Davis, P. J. (2013). The positive effects of mindfulness on self-esteem. The Journal of Positive Psychology, 8(5), 376-386. https://doi. org/10.1080/17439760.2013.807353.

Randal, C., Pratt, D., \& Bucci, S. (2015). Mindfulness and self-esteem: A systematic review. Mindfulness, 6(6), 1366-1378. https://doi.org/10.1007/s12671-015 0407-6.

Reid, R. C., Temko, J., Moghaddam, J. F., \& Fong, T. W. (2014). Shame, rumination, and self-compassion in men assessed for hypersexual disorder. Journal of Psychiatric Practice, 20(4), 260-268. https://doi.org/10.1097/01.pra.0000452562.98286.c5.

Rostosky, S. S., Dekhtyar, O. D., Cupp, P. K., \& Anderman, E. M. (2008). Sexual self-concept and sexual self-efficacy in adolescents: A possible clue to promoting sexual health. The Journal of Sex Research, 45(3), 277-286. https://doi.org/10.1080/00224490802204480.

Ruedy, N. E., \& Schweitzer, M. E. (2010). In the moment: The effect of mindfulness on ethical decision making. Journal of Business Ethics, 95(1), 73-87.

Schonert-Reichl, K. A., \& Lawlor, M. S. (2010). The effects of a mindfulness-based education program on pre- and early adolescents' well-being and social and emotional competence. Mindfulness, 1(3), 137-151. https://doi.org/10.1007/s12671-010-0011-8.

Shapiro, S. L., Jazaieri, H., \& Goldin, P. R. (2012). Mindfulness-based stress reduction effects on moral reasoning and decision making. The Journal of Positive Psychology, 7(6), 504-515. https://doi.org/10.1080/17439760.2012.723732.

Spano, S. (2004). Stages of adolescent development. Retrieved from http://citeseerx.ist.psu.edu/viewdoc/download?doi $=10.1 .1 .625 .9586 \&$ rep $=$ rep $1 \&$ type $=$ pdf.

StataCorp (2017). Stata statistical software: Release 15. College Station, TX: StataCorp LP.

Tan, E. S., \& Yarhouse, M. A. (2010). Facilitating congruence between religious beliefs and sexual identity with mindfulness. Psychotherapy: Theory, Research, Practice, Training, 47(4), 500-511. https://doi.org/10.1037/a0022081.

Tan, L. B. (2016). A critical review of adolescent mindfulness-based programmes. Clinical Child Psychology and Psychiatry, 21(2), 193-207. https://doi.org/10.1177/ 1359104515577486.

Tan, L. B. G., \& Martin, G. (2016). Mind full or mindful: A report on mindfulness and psychological health in healthy adolescents. International Journal of Adolescence 
and Youth, 21(1), 64-74. https://doi.org/10.1080/02673843.2012.709174.

Teper, R., Segal, Z. V., \& Inzlicht, M. (2013). Inside the mindful mind: How mindfulness enhances emotion regulation through improvements in executive control. Current Directions in Psychological Science, 22(6), 449-454. https://doi.org/10.1177/0963721413495869.

Voelker, D. K., Petrie, T. A., Huang, Q., \& Chandran, A. (2019). Bodies in Motion: An empirical evaluation of a program to support positive body image in female collegiate athletes. Body Image, 28, 149-158. https://doi.org/10.1016/j.bodyim.2019.01.008.

Wei, M., Tsai, P., Lannin, D. G., Du, Y., \& Tucker, J. R. (2015). Mindfulness, psychological flexibility, and counseling self-efficacy: Hindering self-focused attention as a mediator. The Counseling Psychologist, 43(1), 39-63. https://doi.org/10.1177/0011000014560173.

Welsh, D. P., Haugen, P. T., Widman, L., Darling, N., \& Grello, C. M. (2005). Kissing is good: A developmental investigation of sexuality in adolescent romantic couples. Sexuality Research and Social Policy, 2(4), 32-41.

Widman, L., Choukas-Bradley, S., Noar, S. M., Nesi, J., \& Garrett, K. (2016). Parent-adolescent sexual communication and adolescent safer sex behavior: A metaanalysis. JAMA Pediatrics, $170(1), 52-61$.

Woo, J. S. T., Brotto, L. A., \& Gorzalka, B. B. (2011). The role of sex guilt in the relationship between culture and women's sexual desire. Archives of Sexual Behavior, 40(2), 385-394. https://doi.org/10.1007/s10508-010-9609-0.

Zhang, C. Q., Si, G., Chung, P. K., \& Gucciardi, D. F. (2016). Mindfulness and burnout in elite junior athletes: The mediating role of experiential avoidance. Journal of Applied Sport Psychology, 28(4), 437-451. https://doi.org/10.1080/10413200.2016.1162223. 